\title{
Gestalt-terapia e Empoderamento Feminino na Relação Terapêutica: Reverberações a partir do Atendimento Psicoterápico entre Mulheres
}

\section{Gestalt Therapy and Female Empowerment in the Therapeutic Relationship: Reverberations from Psychotherapy among Women}

\section{Terapia Gestalt y Empoderamiento Femenino en la Relación Terapéutica: Reverberaciones de la Atención Psicoterapéutica entre Mujeres}

\section{Giovana Fagundes Luczinski*}

Universidade Federal de Pelotas - UFPel, Pelotas, Rio Grande do Sul, Brasil

\section{Keyth Vianna**}

Universidade do Estado do Rio de Janeiro - UERJ, Rio de Janeiro, Rio de Janeiro, Brasil

\section{Renata Parente Garcia***}

Centro Universitário Augusto Motta - Unisuam, Rio de Janeiro, Rio de Janeiro, Brasil

\section{Vanessa Hime Nunes****}

Rio de Janeiro, Rio de Janeiro, Brasil

\section{Alexandra Tsallis****}

Universidade do Estado do Rio de Janeiro - UERJ, Rio de Janeiro, Rio de Janeiro, Brasil

\begin{abstract}
RESUMO
Este artigo tem por objetivo compartilhar possíveis reverberações da relação terapêutica, dentro da abordagem gestáltica, no processo de empoderamento feminino em psicoterapia. Partindo da ênfase relacional dada pela proposta teórica da Gestalt-terapia, este texto surge das vivências das autoras em seus consultórios de psicologia, refletindo sobre os desdobramentos dos encontros. Neste contexto, uma escuta atenta revela que os reflexos da cultura patriarcal são notórios nas demandas trazidas pelas mulheres que chegam ao setting terapêutico. Desde as insatisfações com o próprio corpo às dúvidas sobre escolha profissional; das relações conjugais às experiências (ou não) de maternidade, entre outras questões, observamos as exigências de uma sociedade machista ecoando sobre corpos femininos que, muitas vezes, incapazes de dar conta do "você deveria/não deveria", adoecem. Na contramão dos "deverias", a Gestalt-terapia nos instrumentaliza, através da relação terapêutica, a buscar, com cada mulher,
\end{abstract}


seu modo próprio de existir-no-mundo, reconhecendo suas necessidades e construindo formas de atendê-las. Com isso, testemunhamos movimentos singulares de empoderamento feminino, os quais podem reverberar coletivamente nos contextos em que essas mulheres se posicionam e tecem novos encontros.

Palavras-chave: gestalt-terapia, empoderamento feminino, relação terapêutica.

\begin{abstract}
This article aims to share possible reflections about the therapeutic relationship, within the gestalt approach, in the process of female empowerment in psychotherapy. Considering the relational emphasis given by the theoretical proposal of Gestalt-therapy, this text emerges from the authors' experiences in their psychology offices, reflecting about the impact of the encounters. In this context, a careful listening reveals that the reflexes of patriarchal culture are notorious in the demands brought by women who reach the therapeutic setting. From dissatisfaction with one's body to doubts about professional choice; from marital relationships to (or not) experiences of motherhood, among other issues, we observe the demands of a chauvinistic society echoing over female bodies that, frequently, are unable to cope with the "you should / shouldn't" and get sick. Contrary to the "shoulds", Gestalt-therapy instructs us, through the therapeutic relationship, to seek with each woman their own way of existing, recognizing their needs and constructing ways to take care of them. Thus, we witness unique movements of female empowerment that can collectively reverberate in the contexts in which these women stand for themselves and meet other people.
\end{abstract}

Keywords: gestalt therapy, female empowerment, therapeutic relationship.

\title{
RESUMEN
}

Este artículo tiene como objetivo compartir las posibles reverberaciones de la relación terapéutica, dentro del enfoque gestáltico, en el proceso de empoderamiento femenino en psicoterapia. Partiendo del énfasis relacional dado por la propuesta teórica de la terapia Gestalt, este trabajo emerge de las experiencias de las autoras en sus consultorios de psicología, reflexionando sobre el desarrollo de los atendimientos. En este contexto, una escucha cuidadosa revela que los reflejos de la cultura patriarcal son notorios en las demandas presentadas por las mujeres que llegan al entorno terapéutico. Desde la insatisfacción con el cuerpo hasta las dudas sobre la elección profesional; desde relaciones matrimoniales hasta (o no) experiencias de maternidad, entre otros problemas, observamos las demandas de una sociedad chovinista que resuena sobre los cuerpos femeninos que, a menudo incapaces de hacer frente al "deberías / no deberías" se enferman. Contrariamente a los "deberes", la terapia Gestalt nos instruye, através de la relación terapéutica, para buscar, con cada mujer, su propia manera de existir en el mundo, reconociendo sus necesidades y construyendo formas de satisfacerlas. Por lo tanto, fuimos testigos de movimientos singulares de empoderamiento femenino, que pueden reverberar colectivamente en los contextos en los que estas mujeres se posicionan y tejen nuevos encuentros.

Palabras clave: terapia gestalt, empoderamiento femenino, relación terapéutica. 
O terapeuta torna-se, na maioria das vezes, acompanhante e, mais raramente, guia de uma enorme jornada. A sensação, de início, é de excitação e susto, já que ele sabe que não pode sair ileso dessa aventura: quando retornar ao ponto de partida, também estará transformado. (Juliano, 1999, p. 22).

A Gestalt-terapia propõe que a psicoterapia aconteça através de um encontro, o mais horizontal possível, entre psicóloga ${ }^{1}$ e cliente, transformando ambas as partes envolvidas. Dá-se o nome de atitude dialógica a esta postura de abertura à alteridade, ao "olho no olho" cuidadoso, disponível e confiante nas potencialidades do outro. A relação terapêutica pressupõe esse encontro que, por sua vez, confirma o próprio ser de cada um, como diz Hycner (1995), psicoterapeuta dedicado às sutilezas dessa "profissão paradoxal", que consiste simultaneamente em uma ciência, um serviço e uma relação. É sobre o encontro intersubjetivo que a psicóloga Jean Clark Juliano versa, poeticamente, no trecho acima, sinalizando os efeitos da perspectiva relacional que embasa a proposta teórico-metodológica da Gestalt-terapia.

Desta feita, este artigo pretende analisar o papel da relação terapêutica, dentro da Gestalt-terapia, no processo de empoderamento das mulheres com as quais nos encontramos em nossos consultórios. As inquietações que nos levaram a este processo de escrita emergem desses encontros clínicos, que são atravessados por palavras e conceitos historicamente construídos, como a categoria mulher e o adjetivo feminino. Tiburi (2018) nos lembra que esses são termos construídos pelo patriarcado, que pressupõem uma essência e uniformidade, que a própria condição humana demonstra não existir. Neste sentido, buscaremos cuidar das palavras e léxicos utilizados em nossas reflexões, visando desnaturalizar conceitos e expectativas.

Observamos que o contexto político, social e cultural da contemporaneidade clama por olhares sensíveis a essas questões, sendo reforçado pela recorrente chegada de mulheres ao setting terapêutico sofrendo uma espécie de "inadequação à própria pele". Trata-se da pele feminina, dos papéis ditos femininos, e da ansiedade gerada pela pretensão de atender a tantas expectativas sociais versus acolher os próprios desejos e necessidades. Nos referimos aqui a um recorte de classe, a mulheres brancas e heterossexuais que buscaram a psicoterapia em nossos consultórios privados, trazendo certas problemáticas em comum, segundo nossas observações.

Cobranças sociais por casamento e maternidade, por exemplo, não estão, muitas vezes, alinhadas às expectativas e possibilidades daquelas que buscam atendimento psicoterápico, gerando grande 
sofrimento. Em muitos momentos, temos a sensação de que pairam sobre suas cabeças cerca de quatro relógios diferentes: o primeiro cronometra o tempo das metas a curto prazo, geralmente profissionais; o segundo marca o tempo certo para se casar; o terceiro aponta o passar dos anos que deixa marcas no corpo afetando a autoestima; e, por fim, o quarto representa o famoso relógio biológico, aquele que dizem anunciar o desejo feminino pela maternidade. Parece também existir uma espécie de balança, dessas de dois pratos, onde um lado abriga o lado prático, objetivo e profissional, e o outro o lado sensível e sonhador com os desejos de se casar, ter filhos e uma casa com cachorro - elementos fortemente presentes no imaginário social. Todas as necessidades parecem conflitantes e urgentes, entre desejos singulares e aqueles aprendidos a partir de tantos estímulos que grande parte das mulheres recebem desde a infância.

A escolha desse tema conversa com o contexto político e social brasileiro no qual, apesar de muitos direitos básicos terem sido conquistados ao longo do tempo, como o direito ao voto, o acesso à educação e à liberdade sexual, ainda existe um longo e necessário caminho a ser percorrido. Além disso, sabemos dos altos índices de violência contra a mulher, desigualdade salarial e assimetria no desempenho das tarefas domésticas. Segundo o $12^{\circ}$ anuário do Fórum Brasileiro de Segurança Pública (2018), 4.539 mulheres foram assassinadas no Brasil em 2017, representando uma taxa de 4,3 mortes para cada 100 mil mulheres, sendo 1.133 casos registrados como feminicídio, enquadrados na lei $13.104 / 2015^{2}$. Inclusive foram registrados 61.032 estupros no mesmo ano, representando um crescimento de $10,1 \%$ em relação a 2016 . No que se refere a lesão corporal dolosa, enquadradas na Lei Maria da Penha (11.340/06), foram registradas 221.238 queixas, o equivalente a 606 casos por dia em 2017. De acordo com o Conselho Nacional de Justiça - CNJ (2017), tramitaram no país em 2018, 4.461 processos de feminicídio, e 1,9 milhão de processos relacionados à violência doméstica representando um aumento de $34 \%$ em relação ao ano de 2016 , ano em que esses crimes passaram a ser acompanhados pelo $\mathrm{CNJ}$.

No que se refere à desigualdade salarial e à participação nas tarefas domésticas, de acordo com o Instituto Brasileiro de Geografia e Estatística - IBGE (2018), em 2016, as mulheres receberam cerca de $3 / 4$ dos rendimentos médios dos homens; enquanto o rendimento médio mensal deles era de $R \$ 2.306,00$, o delas era de $R \$ 1.764,00$. No mesmo ano, as mulheres se dedicaram aos cuidados de pessoas e/ou afazeres domésticos cerca de $73 \%$ a mais de horas do que os homens, sendo 18,1 horas semanais das mulheres contra 10,5 dos homens. Esses dados refletem o lugar de vulnerabilidade que a mulher ainda ocupa na sociedade brasileira. Ademais, cabe ressaltar que a categoria mulher é plural, englobando diversas existências e, 
consequentemente, diferentes níveis de exclusão social. Ribeiro (2019), por exemplo, chama-nos a atenção ao fato de que mulheres negras ganham menos do que homens brancos e negros e menos do que mulheres brancas. E se pensarmos nas mulheres trans, por exemplo, essa diferença fica ainda mais marcante.

Nos relatos clínicos, percebemos que as histórias narradas pelas mulheres que atendemos são, muitas vezes, partilhadas por tantas outras, sendo comuns nos discursos femininos. São casos que expressam necessidades defendidas pelos movimentos feministas desde o século XIX até os dias atuais. Ao mesmo tempo, percebemos relatos frequentemente camuflados pela naturalização de uma cultura machista que, sendo enraizada em discursos e práticas, é reproduzida e perpetuada não só pelo opressor, mas também pelas mulheres oprimidas. As narrativas que testemunhamos nos tocam e descortinam ensinamentos herdados da família, crenças constituídas, experiências pessoais e inquietações diante das relações sociais.

Percebemos, então, que toda essa bagagem existencial nos acompanha na relação terapêutica. Ainda que coloquemos as histórias das clientes como protagonistas, deixando nossas experiências pessoais "entre parênteses", conforme proposto por Husserl (2006), nossas vivências femininas também estarão ali. Tal constatação se encontra presente nos pressupostos fenomenológicos que embasam a compreensão do encontro intersubjetivo na abordagem gestáltica. Não há neutralidade nas relações, já que estamos historicamente situadas e conectadas. Nos encontros entre duas mulheres - terapeuta e cliente - todo esse conteúdo, embora não se torne figura, serve de combustível para a sensibilidade e para a qualidade da presença, termo caro à prática da Gestalt-terapia. Conforme Ginger e Ginger (1995) afirmam, essa bagagem invisível, não-dita, toca o outro de forma sensível, de forma que ele se sinta ". . . reconhecido como sujeito, como 'interlocutor válido' e não como um simples objeto de interesse profissional [grifos dos autores] de um terapeuta consciencioso, mas indiferente." (p. 151).

A nossa feminilidade, no encontro com outras feminilidades, performa um tipo de relação singular que, por sua vez, mobiliza esses femininos que estão em ambos os lados da relação. No ambiente psicoterapêutico, as mulheres são instigadas a falarem de si por si mesmas, contando a própria história. Para isso, faz-se necessário construir uma nova gramática, que as expresse e não reproduza acriticamente o discurso hegemônico: o patriarcal. Então, novas feminilidades podem surgir desses encontros, deslocando préconceitos e forjando outros modos de experienciar o feminino. Isso nos leva a pensar a relação terapêutica, seguida da noção de empoderamento. Como dobra dessa reflexão, consideramos os possíveis diálogos entre a prática clínica e a ação social. 


\section{Relação terapêutica: clientes e terapeutas em processo}

Com a cumplicidade do terapeuta, um diálogo começa a se tornar possível, indo até o ponto em que a história pode ser ressignificada. Essa ressignificação, essa mudança de olhar, ajuda o cliente a se reaproximar do seu mundo. (Juliano, 2010, p. 20).

Como já fora destacado, para a Gestalt-terapia somos seres relacionais, isto é, enquanto sujeitos, nos constituímos em relação. Essa premissa está ancorada em correntes de pensamento que precederam o surgimento dessa abordagem teórica em psicologia, enfatizando a dimensão ontológica de ser no mundo. A fenomenologia e o existencialismo fornecem a fundamentação filosófica necessária à essa compreensão, demonstrando que pessoa e mundo se constituem mutuamente. Deste modo, a relação terapêutica, ou relação dialógica, como também é nomeada, é o eixo central da abordagem gestáltica, como destaca Freitas (2016), inspirada em Laura Perls. Sendo assim, a relação terapêutica acontece no encontro entre dois mundos: cliente e terapeuta que, por sua vez, também compartilham um mundo comum, historicamente situado.

O movimento em psicoterapia acontece quando a cliente é "tocada" pelas reverberações que emergem na/da relação terapêutica, estando permeável às afetações geradas pela presença da alteridade. 0 encontro forja possibilidades de existência em ambos os lados da relação. E foi isso que aconteceu conosco! Receber mulheres em nossos consultórios nos mobilizou quanto às questões de gênero que essas traziam. Nós, psicoterapeutas, como muitas mulheres, fomos educadas para formar um par heteronormativo, no ideário romântico do patriarcado, ou, em contrapartida, fomos incentivadas a "não depender de homem nenhum para viver", reforçando o individualismo da sociedade de massas. Essa segunda opção sugere que as mulheres sejam como se espera dos homens: exercendo poder, autoridade e respeito através da força de uma credencial. Ambos os extremos se tornam facilmente reféns da lógica hegemônica, seja do lugar da submissão, do consumo, ou do empenho em gerar força de trabalho através da competitividade, contribuindo para a produtividade infindável da ordem social instalada.

Adentram nossos settings terapêuticos mulheres que nos remetem à imagem de um ser sem voz e cheio de braços. Muitas vezes, nas suas múltiplas funções de mãe, dona de casa, esposa e profissional, sentem dificuldade em expressar suas vontades, predominando a satisfação das vontades alheias. Trabalhar em suas áreas de atuação, ajudar os filhos com as lições de casa, cuidar das tarefas domésticas, 
ir ao supermercado, ligar para familiares e amigos, exercendo diferentes formas de cuidado, são exemplos de tarefas assumidas como se pertencessem naturalmente ao universo feminino. Ser multitarefas é considerada uma qualidade feminina, permitindo que os homens exerçam o foco em suas atividades, sem acumular tantas funções. No entanto, segundo Han (2017) o desenvolvimento de múltiplas tarefas, a perda da possibilidade de contemplação e concentração, mostram um retrocesso na evolução da humanidade, gerando cansaço, dispersão e adoecimento psíquico.

Mulheres de uma geração mais jovem, com as quais nos encontramos, consideram-se satisfeitas com sua trajetória e ascensão profissional, buscando, inicialmente, se conhecer, se organizar e atingir um aprimoramento. Do mesmo modo, tencionam com o processo terapêutico a possibilidade de aprender a controlar sua ansiedade diante da máxima hegemônica de que o lado emocional tende a atrapalhar o progresso na carreira. Simultaneamente, demonstram que o desejo de formar uma família conflita com a imagem de uma profissional competente e independente, como se fossem duas pessoas diferentes que não pudessem conviver no mesmo ambiente, que dirá no mesmo corpo! Tal reconhecimento pode ser algo amedrontador, mas entrar em contato com essa necessidade e com as próprias crenças faz com que se possa mobilizar energia para a conquista de objetivos pessoais de forma mais consciente e singular. Tal consciência remete ao processo de awareness, um ponto fundamental na proposta da Gestalt-terapia.

Estar aware significa, literalmente, "tornar-se consciente" de algo. Utiliza-se a palavra em sua língua original, pois trata-se de um termo muito mais amplo do que sua tradução permite compreender. Significa tomar contato global com um determinado processo, tanto no nível racional, quanto no afetivo. Yontef (1998) entende awareness enquanto uma forma de experiência, podendo ser definida como ". . . estar em contato com a própria existência, com aquilo que é [grifo do autor]." (p. 30). Neste sentido, a mera apreensão intelectual de uma (suposta) verdade não poderia gerar mudanças de fato, pois é preciso apreender o mundo de forma integrada, vivencial, articulando pensamentos, valores e sensações. Por isso, o trabalho psicoterapêutico, que parte do encontro intersubjetivo entre terapeuta e cliente, passa pelo contato aprofundado com os temas abordados, de forma a compreender, desconstruir e ressignificar.

Frazão (2005) ressalta que a qualidade da relação será empobrecida se a pessoa não estiver aware, ou seja, presente em sua apropriação da experiência. Cabe à terapeuta, então, um convite constante ao encontro com as reverberações que surgem na psicoterapia. Esse movimento contribui para a ampliação do campo perceptivo e experiencial da cliente, possibilitando interações mais nutritivas e desenvolvimento pessoal. 
A trilha a percorrer na psicoterapia pode engendrar um reencontro consigo e um modo próprio de ser e estar no mundo diante das demandas socialmente construídas. Com isso, dizemos que é possível experimentar a reconfiguração do campo a partir do encontro dialógico. Um dos autores de referência dessa abordagem, Yontef (1998), define campo como "Uma totalidade de forças mutuamente influenciáveis que, em conjunto, formam uma fatalidade interativa unificada." (p. 185). Ou seja, organismo e ambiente são indissociáveis e mutuamente constitutivos. Essa relação que aproxima, afasta, cria, destrói, recria, renova, inventa, etc., acontece na fronteira entre o self e o outro. É neste "entre" que ocorre a experiência, o crescimento e a mudança, merecendo redobrada atenção das terapeutas.

A problematização do espaço do "entre" foi trazida à cena no âmbito da filosofia por Buber (2001), conhecido como o filósofo da relação. Ele aborda a dimensão inter-humana que permeia as relações pessoa-a-pessoa e transforma ambas as partes envolvidas, caracterizando o que denomina de relação "eu-tu". Nessa perspectiva, alguém que se abre para o encontro, dizendo "Tu" ao outro, coloca-se em uma zona de devir e movimento, podendo vivenciar uma mudança qualitativa. Não é raro que gestalt-terapeutas se inspirem na ontologia buberiana para compreender o encontro transformador que acontece na clínica, buscando construir atitudes facilitadoras para seu acontecimento. Destacamos aqui a horizontalidade e a abertura mútua descritas pelo filósofo como condições para a relação. É evidente para nós que a psicoterapia se constitui enquanto uma prática científica e, por isso, está atravessada por relações de saber-poder. Reconhecemos que terapeuta e cliente ocupam lugares distintos nessa relação, porém, na Gestalt-terapia, trabalhamos por uma prática clínica capaz de considerar tal assimetria, com atenção para que se possa construir um caminho de diálogo e cuidado a partir das reverberações.

Estar disponível para o encontro é arriscar-se. Enquanto terapeutas, sabemos que não saímos ilesas dessa aventura, mas mobilizadas e atravessadas por diferentes intensidades. Percebemos que nossa condição de mulheres, conscientes do contexto em que estamos inseridas, nos investe de uma escuta solidária às nossas clientes. Passamos a ocupar um lugar de partilha no que se refere às reivindicações trazidas ao setting terapêutico, ao mesmo tempo em que temos a oportunidade de rever e desconstruir nossa própria misoginia. Na clínica, passamos a estar com mulheres em um espaço de interesse mútuo em relação a um problema comum, historicamente construído, criando potências de encontro com aquilo que nos aproxima e com o que nos diferencia. O processo terapêutico se beneficia dessa qualidade de escuta em que a terapeuta é capaz de estar sintonizada consigo mesma e com aquelas que buscam 
atendimento psicológico, respeitando as diferenças existentes e se abrindo para uma experiência nova. Em Gestalt-terapia chamamos isso de contato que, de acordo com Ribeiro (2006), é

. . fruto da entrega recíproca de duas pessoas ou coisas, dispostas a serem iguais pela troca das diferenças, como resultado de uma nova relação que cria a sensação de que eu sou eu, de que o outro é o outro e de que ambos são seres complementares. (p. 93).

Apesar da citação acima trazer a ideia de complementaridade, precisamos ressaltar que o contato não se dá, sempre, de forma harmoniosa, pois o conflito faz parte das relações, ressaltando as diferenças. Há um pressuposto que guia as abordagens existenciais e a Gestalt-terapia proveniente da perspectiva fenomenológica: nossa condição ontológica marca um funcionamento humano em comum, apesar de articulações singulares diante das afetações vividas na existência (Luczinski \& Ancona-Lopez, 2010). Tal condição nos permite ouvir, dialogar e encontrar, mas também gera angústias, estranhamentos e desamparo. Por isso, Buber (2001) caracterizava a situação de diálogo como caminhar em uma "estreita aresta" estando atento aos atravessamentos, conflitos, diferenças e desafios que a escuta coloca. É preciso transitar entre aquilo que aproxima e aquilo que distancia, sabendo que há uma condição em comum, mas infinitas formas de ser mulher. São as potencialidades e limites da construção da singularidade que torna única cada experiência do feminino.

Na proposta da Gestalt, Perls (1977) destaca a importância de considerarmos o mundo em que vivemos como parte de nós: "Aonde quer que vamos, levamos sempre uma espécie de mundo conosco." (p. 21). Além disso, é na superposição do "mundo da cliente" com o "mundo da terapeuta" que acontece a nossa comunicação. O que temos acompanhado em nossos consultórios são mulheres em sofrimento, buscando se ajustar ante as suas necessidades com as ferramentas de que dispõem. O papel da psicoterapia na abordagem gestáltica abrange a ampliação do movimento existencial no contato com o mundo, trabalhando com o trânsito entre as polaridades. A psicoterapia pode acontecer no espaço do consultório, mas é no mundo que nos experimentamos. Nesse sentido, ao acompanhar mulheres em suas jornadas de autoconhecimento, compreendemos a relação terapêutica enquanto veículo de fortalecimento dessas feminilidades subjugadas, vivenciando a ampliação do empoderamento feminino. 


\section{Empoderamento feminino e relação terapêutica}

"Quando uma mulher empodera a si, tem condições de empoderar a outras." (Ribeiro, 2017, para. 5).

O termo Empoderamento é considerado um neologismo vindo da tradução da palavra em inglês: empowerment. No Dicionário Aurélio ${ }^{3}$ encontramos a palavra "Empoderar" que significa: dar ou adquirir poder ou mais poder e, também, a palavra "Empoderamento" como o ato ou efeito de empoderar ou empoderar-se. Segundo Berth (2019), o termo empoderamento foi cunhado pelo sociólogo estadunidense Julian Rappaport, significando o processo de adquirir liberdade e poder para se fazer o que se quer ou controlar o que acontece a você. Para isso, o autor destaca o quão fundamental é instrumentalizar os grupos oprimidos para que tenham autonomia (Rappaport, 1997 como citado em Berth, 2019).

Por outro lado, Paulo Freire não acreditava ser necessário fornecer ferramentas para que os grupos minoritários se empoderem, pois as próprias pessoas deveriam empoderar a si próprias, através de uma consciência crítica da realidade e uma prática transformadora. Sua contribuição destaca-se por ressaltar o empoderamento em sua dimensão coletiva e social, isto é, não se trata de um processo de natureza individual, tampouco de autolibertação; para ele a libertação é um ato social (Freire \& Shor, 1986). Deste modo, entendemos empoderamento enquanto uma prática coletiva forjada no meio social, "O qual envolve, necessariamente, um desequilíbrio nas relações de poder na sociedade." (Baquero, 2012, p. 181).

Berth (2019) destaca que, na década de 1980, parte do movimento feminista insere um novo elemento na discussão sobre empoderamento: a interseccionalidade. Ressalta que haveria um limite nas discussões precedentes por considerar o oprimido enquanto um conceito abstrato, isto é, destituído de categorias como raça, gênero e sexualidade. Nesse texto não nos dedicamos à essa discussão, mas tal concepção é essencial para se pensar as desigualdades sociais experienciadas pelos grupos minoritários, dentre eles, a opressão vivida pelas mulheres em nosso contexto sócio-histórico-cultural.

De acordo com Baquero (2012) o conceito de empoderamento somente passará a expressar a luta por direitos civis de negros, mulheres e homossexuais, por exemplo, a partir da segunda metade do século XX. A luta desses movimentos, do ponto de vista psicológico, refletia o conceito norte-americano de self made man, ou seja, de se realizar através do esforço pessoal. O empoderamento feminino tem essa raiz, na concepção da conquista de um poder interno através do fortalecimento da autoestima e da capacidade de 
ampliar conquistas pessoais. Berth (2019) ressalta que quando falamos em empoderar alguém, estamos nos referindo a uma:

Condução articulada de indivíduos e grupos por diversos estágios de autoafirmação, autovalorização, autorreconhecimento e autoconhecimento de si mesmo e de suas mais variadas habilidades humanas, de sua história, e principalmente de um entendimento quanto a sua posição social e política e, por sua vez, um estado psicológico perceptivo do que se passa ao seu redor. (p. 21).

É preciso certo cuidado com a proposta de empoderamento que restringe à mulher o dever de empoderar-se. Tiburi (2018) afirma que é inócuo proclamar o feminismo sem lutar pela transformação de toda a sociedade. Por isso, precisamos romper com a ideia de um empoderamento exclusivamente individual, ou como ". . . algo autocentrado, parte de uma visão liberal, ou ser somente a transferência de poder." (Ribeiro, 2017, para. 2). A vida em sociedade está permeada por relações de poder que, quando enrijecidas em apenas um polo, impedem os movimentos de transformação tanto individual quanto social.

Algumas mulheres nos procuraram, enquanto psicoterapeutas, nos anos de 2017 e 2018, trazendo queixas de fobia, ansiedade e depressão. Ao serem observadas de maneira mais cuidadosa, embora preservadas suas características singulares, essas mulheres possuem um traço comum: a influência da cultura patriarcal, que historicamente reduziu a mulher a uma espécie humana de segunda categoria para poder dominá-la e, ao longo do tempo, foi subvertendo tudo que fosse relacionado ao feminino. Na história da humanidade, durante o período agrícola, essas características atribuíam à mulher certo prestígio, pois se vivia da terra e a procriação fortalecia os clãs. Como destaca Beauvoir (2016):

A desvalorização da mulher representa uma etapa necessária na história da humanidade, porque não era de seu valor positivo, mas de sua fraqueza que ela tirava seu prestígio; nela encarnavam-se os inquietantes mistérios naturais: o homem escapa de seu domínio quando se liberta da natureza. (p. 110).

Hoje ainda sofremos os efeitos dessa desvalorização histórica, fortemente presente na cultura ocidental desde o pensamento dos gregos antigos que, como demonstra Arendt (2007), separavam espaço público e privado. O primeiro pertencia ao domínio dos homens, que podiam exercer a política entre iguais, sendo senhores de seus lares, nos quais as mulheres e escravos dedicavam-se apenas à manutenção da vida. A proximidade da mulher em relação à 
natureza era sentida como inferioridade em tempos no qual o intelecto e a racionalidade emergiam como valores.

Ao longo dos séculos, muitas mudanças tiveram passagem, com maior emancipação feminina e a entrada da mulher no mercado de trabalho formal, saindo do âmbito exclusivamente privado. No entanto, chegam até nós mulheres que se desenvolveram profissionalmente, mas junto aos desafios da carreira, acumulam sozinhas as responsabilidades pelos cuidados com a casa e com os filhos, mesmo quando dividem a residência com alguém. São mulheres que insistentemente sentem que precisam provar sua capacidade intelectual, menosprezando seu lado sensível, artístico e afetivo; são mulheres que estão sempre zelando por tudo e por todos, e entram em conflito com suas próprias necessidades de serem cuidadas, como se demonstrações de afeto, fragilidades e incompletudes se caracterizassem como algo menor, ruim e sem valor. No entanto, tais características, que evidenciam a vulnerabilidade e a ambiguidade, são próprias à condição humana, como afirmam o existencialismo e a fenomenologia (Arendt, 2002; Buber, 2001; Merleau-Ponty, 1975).

Como nos lembra Tiburi (2018), o feminismo é o movimento que avalia criticamente essas questões para além das naturalizações do que se configura ser mulher e das características do feminino. Há nesse pensamento uma busca pela singularidade e pela diversidade que nos caracteriza como seres humanos, que é suprimida pelo modo de funcionamento da sociedade capitalista, individualista e meritocrática.

Na prática clínica, entendemos a palavra empoderar como um verbo intransitivo, um processo onde a ação acontece no encontro da cliente com o contexto no qual está inserida. Como consequência, é possível forjar novas possibilidades de escolha, de decisão, de caminho a ser seguido, de estabelecer limites nas relações, de construir o próprio futuro de forma autônoma. Coadunamos com Campos e Campos (2006) quando conceituam autonomia como tomar conhecimento, de forma ampliada, da teia de relacionamentos à qual uma pessoa pertence, percebendo-se interdependente em um sistema vivo, em redes. Roso e Romanini (2014) destacam que "As mulheres podem se libertar de alguns atos individuais cotidianos que as oprimem (e.g. marido que agride, ter espaço no mercado de trabalho, etc.). Todavia, elas só conseguirão transformar as relações injustas de gênero se juntarem suas forças." (p. 89). O aporte teórico da Gestalt-terapia e de suas bases filosóficas, como a fenomenologia, nos ensinam que esse processo não é algo individual ou intrapsíquico, mas relacional. Sendo assim, todo desenvolvimento será inerentemente social. Apenas como parte de um grupo, inserida em uma comunidade, permeada por certas práticas, é possível ampliar as 
possibilidades de ação, tornando-se agente e corresponsável pela própria história.

\section{Abrindo uma gestalt}

A Gestalt-terapia valoriza mais a forma do que o conteúdo, inspirando a ver o mundo em cores, movimentos, sutilezas, sons, sabores, cheiros e toques. Sua proposta clínica permite explorar os sentidos, experimentar e contatar o mundo com mais riqueza, o que contribui para o processo de empoderamento da forma como o entendemos.

Frazão e Rocha (2005) destacam que as relações entre homens e mulheres se transformaram e, por isso, discutir as relações de gênero exige novas perspectivas, tanto teóricas quanto metodológicas. No que se refere ao processo de empoderamento feminino, consideramos a Gestalt-terapia um aporte importante para compreender o movimento existencial e social das mulheres nos desafios que enfrentam nesse percurso. Vale lembrar que as reflexões que tecem este escrito emergem dos encontros que tivemos com algumas mulheres na clínica. Foram mulheres que nos inspiraram a pensar as possibilidades da relação terapêutica no processo de empoderamento, uma vez que foi o que testemunhamos nos encontros. Desse modo, entendemos que as discussões disparadas tem caráter situacional e encarnado.

Numa sociedade patriarcal, tende-se a menosprezar as necessidades das mulheres em relação às necessidades dos homens e, assim, as possibilidades femininas vão sendo "atrofiadas" por não serem reconhecidas e valorizadas. A relação terapêutica se mostrou como grande aliada no processo de empoderamento feminino ao acompanhar o contato das mulheres com o contexto à sua volta, consigo mesmas e com suas possibilidades de atuação no mundo. Sabemos que a escuta clínica está ancorada na relação entre subjetividade e mundo circundante, sendo sempre situada e implicada.

Clientes e terapeutas são parte de uma teia mais ampla de relações que evidencia a dimensão inter-relacional e plural da existência, tornando fundamentais as trocas e a ampliação do diálogo para o âmbito coletivo. Sendo assim, o que acontece na psicoterapia é exercitar algo próprio da condição humana que se empobreceu na sociedade de massas: a transformação através do encontro. A diminuição do diálogo, na perspectiva buberiana, está relacionada à supressão do tempo para estar qualitativamente com o outro, ao excesso de demandas, e ao modo técnico de funcionamento da vida. Esse se reflete nas relações, que passam a ser hierarquizadas e instrumentalizadas, reduzindo seu potencial transformador. 
Encerramos momentaneamente essa discussão, lembrando que as relações entre mulheres, e dessas com os seus contextos, refletem relações de poder, expressas nos atravessamentos de classe, gênero e raça. Trabalhos futuros, aprofundando 0 conceito de interseccionalidade, em diálogo com a noção de empoderamento, podem ampliar essa discussão. A ampliação de modos de estar no mundo, as possibilidades e o exercício do empoderamento requerem ações coletivas, que são inerentemente políticas. O corpo feminino é marcado por lugares reservados a ele no pensamento hegemônico, que condicionam modos de ser. Através da relação terapêutica, testemunhamos processos de empoderamento que emergiram dos encontros entre mulheres que se reconheceram em suas semelhanças e diferenças, estabelecendo contato e construindo momentos de awareness. As reverberações desencadeadas pelo processo terapêutico se fortalecem ao romper o âmbito estritamente individual, afinal, para que as mulheres se emancipem e se empoderem é preciso encontrar caminhos para mobilizar os coletivos que constituem uma dada sociedade.

\section{Referências}

Arendt, H. (2002). A vida do espírito: o pensar, o querer, o julgar. Rio de Janeiro, RJ: Relume Dumará.

Arendt, H. (2007). A condição humana. Rio de Janeiro, RJ: Forense Universitária.

Baquero, R. V. A. (2012). Empoderamento: instrumento de emancipação social? - Uma discussão conceitual. Revista Debates, 6(1), 173-187. doi: 10.22456/1982-5269.28218

Beauvoir, S. (2016). O segundo sexo: fatos e mitos. Rio de Janeiro, RJ: Nova Fronteira.

Berth, J. (2019). Empoderamento. São Paulo, SP: Pólen Livros.

Buber, M. (2001). Eu e Tu. São Paulo, SP: Centauro.

Campos, R. T. O., \& Campos, G. W. S. (2006). Co-construção de autonomia: o sujeito em questão. In G. W. S. Campos et al. (Eds.), Tratado de saúde coletiva (pp. 669-688). São Paulo, SP: Hucitec.

Conselho Nacional de Justiça. (2017). Agência CNJ de notícias: CNJ divulga dados do Judiciário sobre violência contra a mulher [site]. Recuperado de http://www.cnj.jus.br/noticias/cnj/85640-cnj-publica-dadossobre-violencia-contra-a-mulher-no-judiciario

Fórum Brasileiro de Segurança Pública. (2018). Anuário do Fórum Brasileiro de Segurança Pública [site]. Ano 11. Recuperado de http://www.forumseguranca.org.br/wp- 
content/uploads/2019/03/Anuario-Brasileiro-de-SegurançaPública-2018.pdf

Frazão, L., \& Rocha, S. (2005). Gestalt e Gênero: Configurações do masculino e feminino na contemporaneidade. Campinas, SP: Livro Pleno.

Freire, P., \& Shor, I. (1986). Medo e ousadia - O cotidiano do professor. Rio de Janeiro, RJ: Paz e Terra.

Freitas, J. R. C. B. (2016). A relação terapeuta-cliente na abordagem gestáltica. Revista Virtual IGT na Rede, 13(24), 85-104. Recuperado de https://www.igt.psc.br/ojs/viewarticle.php?id=565\&layout $=$ htm I

Ginger, S., \& Ginger, A. (1995). Gestalt: uma terapia do contato. São Paulo, SP: Summus.

Han, B. (2017). Sociedade do Cansaço. Petrópolis, RJ: Vozes.

Husserl, E. (2006). Ideias para uma fenomenologia pura e para uma filosofia fenomenológica: Introdução geral à fenomenologia pura. Aparecida: Ideias \& Letras.

Hycner, R. (1995). De pessoa a pessoa. São Paulo, SP: Summus.

Instituto Brasileiro de Geografia e Estatística (2018). Estatísticas de gênero: indicadores sociais das mulheres no Brasil. Estudos e Pesquisas. Informação Demográfica e Socioeconômica [site]. Número $38 . \quad$ Recuperado de https://agenciadenoticias.ibge.gov.br/media/com_mediaibge/ar quivos/9d6f4faeda1f1fb7532be7a9240cc233.pdf

Juliano, J. C. (1999). A arte de restaurar histórias: o diálogo criativo no caminho pessoal. São Paulo, SP: Summus.

Juliano, J. C. (2010). A vida, o tempo, a psicoterapia. Escritos de Jean Clark Juliano. São Paulo, SP: Summus.

Luczinski, G. F., \& Ancona-Lopez, M. (2010). A psicologia fenomenológica e a filosofia de Buber: o encontro na clínica. Estudos de Psicologia, 27(1), 75-82. doi: 10.1590/S0103$166 \times 2010000100009$

Merleau-Ponty, M. (1975). A estrutura do comportamento. Belo Horizonte, MG: Interlivros.

ONU Mulheres Brasil. (2016). Diretrizes nacionais feminicídio: Investigar, processar e julgar com perspectiva de gênero as mortes violentas de mulheres [site]. Recuperado de http://www.onumulheres.org.br/wpcontent/uploads/2016/04/di retrizes_feminicidio.pdf

Perls, F. (1977). Gestalt-terapia explicada. São Paulo, SP: Summus.

Ribeiro, D. (2017). O que é o empoderamento feminino. Carta Capital [site]. Recuperado

https://www.cartacapital.com.br/revista/971/o-que-e-oempoderamento-feminino

Ribeiro, D. (2019). Lugar de fala. São Paulo, SP: Pólen. 
Ribeiro, J. (2006). Vade-mécum de Gestalt-terapia: conceitos básicos. São Paulo, SP: Summus.

Roso, A., \& Romanini, M. (2014). Empoderamento individual, empoderamento comunitário e conscientização: um ensaio teórico. Psicologia e Saber Social, 3(1), 83-95. doi: 10.12957/psi.saber.soc.2014.12203

Tiburi, M. (2018). Feminismo em comum: para todas, todes e todos. Rio de Janeiro, RJ: Rosa dos Tempos.

Yontef, G. (1998). Processo, diálogo e awareness: ensaios em Gestalt-terapia. São Paulo, SP: Summus.

\section{Endereço para correspondência \\ Giovana Fagundes Luczinski \\ Avenida Duque de Caxias, 250, Fragata, CEP 96030-001, Pelotas - RS, Brasil \\ Endereço eletrônico: giovana.luczinski@gmail.com}

\section{Keyth Vianna}

Rua São Francisco Xavier, 524, sala 10019, bloco F, Maracanã, CEP 20550-900, Rio de Janeiro - RJ, Brasil

Endereço eletrônico: keythvianna@hotmail.com

Renata Parente Garcia

Avenida Olof Palme 555, apto 209, bl. lake Camorim, CEP 22783-119, Rio de Janeiro - RJ, Brasil

Endereço eletrônico: renatagarcia_psi@yahoo.com.br

\section{Vanessa Hime Nunes}

Secretaria de Graduação da Psicologia

Rua São Francisco Xavier, 524, $10^{\circ}$ andar, bloco B, sala 10006, Maracanã, CEP 20550-900, Rio de Janeiro - RJ, Brasil

Endereço eletrônico: vanessahime@gmail.com

\section{Alexandra Tsallis}

Secretaria de Graduação da Psicologia

Rua São Francisco Xavier, 524, $10^{\circ}$ andar, bloco B, sala 10006 - Maracanã, CEP 20550-900, Rio de Janeiro - RJ, Brasil

Endereço eletrônico: atsallis@gmail.com

Recebido em: 13/10/2019

Reformulado em: 28/12/2019

Aceito em: 03/01/2020

\section{Notas}

* Psicóloga (UFMG), Mestre em Psicologia Clínica (PUC-SP), e Doutora em Psicologia Social (UERJ). Professora Adjunta na Universidade Federal de Pelotas.

** Psicóloga (UERJ), Mestre em Psicologia Social (UERJ), e Doutoranda em Psicologia Social (UERJ).

*** Psicóloga (UFRJ), Mestre em Psicologia (PUC-RJ), Gestalt-terapeuta (Dialógico). Psicóloga clínica, psicóloga do esporte e professora da Unisuam.

**** Psicóloga (Universidade Estácio de Sá), Gestalt-terapeuta (Universidade Santa Úrsula). Psicóloga Clínica atuando em consultório particular.

$* * * * *$ Doutora em Psicologia Social (UERJ / Ecole des Mines - Paris). Professora Adjunta do Departamento de Psicologia Social e Institucional da UERJ. 
1 Neste artigo optamos por escrever no feminino para referenciar psicólogas e psicólogos. Isso porque os encontros que vivenciamos no setting terapêutico, e que inspiram a escrita deste texto, se deram entre mulheres - terapeutas e clientes.

$2 \mathrm{Em} 9$ de março de 2015, a então Presidenta da República, Dilma Rousseff, sancionou a lei 13.104/2015, que altera o Código Penal Brasileiro, passando a prever o feminicídio como uma das circunstâncias qualificadoras do homicídio. Considera-se que o crime deve envolver violência doméstica e familiar, bem como menosprezo ou discriminação à condição de mulher.

3 Dicionário Aurélio Online de Português. (2019). Recuperado de https://dicionariodoaurelio.com/empoderamento

Este artigo de revista Estudos e Pesquisas em Psicologia é licenciado sob uma Licença Creative Commons Atribuição-Não Comercial 3.0 Não Adaptada. 